Revista Destaques Acadêmicos, Lajeado, v. 11, n. 1, 2019. ISSN 2176-3070

DOI: http://dx.doi.org/10.22410/issn.2176-3070.v11i1a2019.2137

http://www.univates.br/revistas

\title{
AS PERSPECTIVAS PROFISSIONAIS DOS ACADÊMICOS DE CONTABILIDADE: COMPARAÇÃO ENTRE BRASIL E PORTUGAL
}

\author{
Michael Juchum ${ }^{1}$, Alexandre André Feil ${ }^{2}$
}

Resumo: Os acadêmicos em contabilidade possuem dúvidas relacionadas ao futuro da profissão, a saber, tipo de atividade disponível, a remuneração, as opções onde trabalhar, o nível de conhecimento exigido, o processo de entrevistas, entre outros. Neste contexto, este estudo objetiva analisar as perspectivas quanto à atuação do profissional contábil pelos acadêmicos de instituição de ensino superior em Portugal, e comparar com estudos no Brasil. O método de pesquisa utilizado é a quantitativa, descritiva e o procedimento técnico survey, por intermédio de questionário. A amostra não probabilística é de 72 acadêmicos do Instituto Politécnico de Leiria de Portugal (IPL). Os principais resultados revelam que o estudo ocorre no período diurno e pós-laboral, não trabalham e aqueles que trabalham não atuam na área contábil, tem pretensão de atuarem na área da contabilidade geral, e em relação a profissão é de atuar em empresa privada e em escritório contábil. Além disso, as variáveis intervenientes que influenciam na expectativa de remuneração e na inserção no mercado de trabalho é a faixa etária dos acadêmicos. Conclui-se que apesar das semelhanças entre a estrutura normativa e de processos da profissão contábil de Portugal e do Brasil, as características relacionadas ao perfil e as perspectivas futuras dos acadêmicos diferem de forma substancial.

Palavras-chave: Perspectivas profissionais. Ciências contábeis. Portugal. Brasil.

\section{INTRODUÇÃO}

A evolução do mercado de trabalho é considerada uma das consequências da globalização e esta pode ser responsável pelo desaparecimento de profissões existentes e do surgimento de novas. A área da contabilidade também insere-se

1 Graduado em Ciências Contábeis pela Universidade UNIVATES.

2 Doutor em Qualidade Ambiental pela Universidade Feevale. Docente do programa de pós-graduação em Sistemas Ambientais Sustentáveis (PPGSAS), mestrado profissional, da Universidade Univates. Docente do curso de Ciências Contábeis do Centro de Gestão Organizacional (CGO) da Univates. 
neste contexto e chegou a ser condenada a desaparecer com o surgimento da informática, porém ainda é considerada indispensável (EPOCA.GLOBO, 2014).

Na profissão contábil a ocorrência de fraudes e erros e a harmonização contábil, acomete o surgimento de mudanças estruturais substanciais (MARQUES; DIAS; SILVA, 2017). Além disso, é uma das áreas que mais oferece oportunidades de mercado (SILVA et al., 2015), mas também há exigências de constante aperfeiçoamento e atualização nesta área, pois o conhecimento contábil não é estático (VIEIRA, 2016). Esta atualização desencadeia uma adaptação às recentes alterações no mercado, a saber, a capacidade de liderança, o convívio com diferentes culturas, conhecimento em idiomas estrangeiros, possuir imagem profissional ética, entre outros (SOUZA; TAVARES, 2013; MARIN; LIMA; NOVA, 2015).

O profissional contábil não executa apenas as obrigações acessórias na atualidade, mas também participa do processo gerencial (CORKERN; PARKS; MORGAN, 2013). Neste processo gerencial o nível de conhecimento intelectual e práxis são essenciais para enfrentar os desafios, identificar novas oportunidades de emprego e desenvolver habilidades e competências para desempenhar suas funções (DEGENHART; TURRA; BIAVATTI, 2016). Portanto, o perfil atual deste profissional agrega múltiplas habilidades e exige a participação no processo de gestão.

As exigências do mercado demandam uma adaptação na formação superior de Ciências Contábeis para capacitação dos profissionais (DEGENHART; TURRA; BIAVATTI, 2016) e as organizações, na atualidade, demandam profissionais contábeis contextualizados, multidisciplinares e abertos à mudanças (CORKERN; PARKS; MORGAN, 2013). Neste sentido, as perspectivas futuras e a automotivação influenciam, de forma significativa, na escolha do curso de contabilidade pelos acadêmicos (UMAR, 2014). Rababah (2016) enfatiza que os fatores motivadores na escolha do curso de contabilidade podem centrar-se na remuneração, disponibilidade e segurança de emprego, promoção profissional e a flexibilidade. Além disso, afirma que a expectativa de carreira influência na decisão da escolha do curso de contabilidade.

Neste contexto, este estudo objetiva analisar as perspectivas futuras dos acadêmicos do Instituto Politécnico de Leiria de Portugal quanto a profissão contábil e sua comparação com o Brasil. O estudo justifica-se pela importância que o profissional contábil possui na sociedade, e além disso, pelo leque do mercado de trabalho desta profissão, o que torna impossível atuar e especializar-se em todas as áreas, mas optar por alguma especifica (SOUZA; TAVARES, 2013). Além disso, o entendimento das perspectivas futuras dos acadêmicos demonstra a direção da profissão contábil, e assim, os acadêmicos, organizações e demais stakeholders se preparam para as mudanças. 


\section{REFERENCIAL TEÓRICO}

\subsection{Desenvolvimento da contabilidade em nível global}

O estudo da história na área da contabilidade permite entender a profissão, sua evolução e influências, e assim, identificar contribuições para o futuro (SILVA; ASSIS, 2015). Luz (2015) enfatiza que a história da contabilidade acompanha a história da própria humanidade, pois a necessidade de proteger e controlar seus bens, levou a civilização buscar meios de registro e controle. Neste sentido, pode-se traçar um paralelo de evolução entre a civilização, os controles e a contabilidade.

Na Idade Média, especificamente em 1202, Leonardo Fibonaci escreveu Liber abaci que retrata o estudo do cálculo aritmético e aborda problemas relacionados com cálculo de lucros, conversão de moedas, entre outros (PEREIRA; FERREIRA, 2016). Na Idade Moderna, em 1458, foi lançamento o livro de Della mercatura et del mercante perfetto, por Benedetto Cotrugli e, em 1494, em Veneza, o Summa de arithmetica, geometria preportioni et proportionalitá, por Frei Luca Pacioli. Portanto, estas obras foram o liminar da evolução da teoria e práxis contábil (LUZ, 2015).

Na Idade Contemporânea, período de 1789 aos dias atuais, a obra $L a$ contabilità applicata alle amministrazioni private e pubbliche, de Franscisco Villa, publicada em 1840, dá ênfase a administração da riqueza e não apenas em seu controle. Na sequência, o principal progresso na contabilidade ocorreu a partir de 1929, com a falência da bolsa de valores de Nova Iorque, que evidenciou a necessidade de uma fixação de padrões internacionais de contabilidade e sua regulamentação (BUGARIM et al., 2013). Além disso, com a retomada do desenvolvimento da economia após a Segunda Guerra Mundial, as informações contábeis tornaram-se indispensáveis, auxiliando investidores na análise das organizações.

\subsection{Evolução da contabilidade em Portugal}

A evolução do pensamento contábil, em Portugal, divide-se em quatro períodos (LIRA, 2011): a) Primeiro período, entre a fundação da nacionalidade e o século XV, abrangendo toda Idade Média: a escrituração contábil adotada em Portugal utilizava-se exclusivamente das partidas simples; b) Segundo período, entre o século XV e o século XVIII, com a coroação de D. José: a maioria já passou a utilizar as partidas dobradas; c) Terceiro período, entre o século XVIII e metade do século XX; e d) Quarto período, a partir da metade do século $\mathrm{XX}$ até os dias atuais.

Alguns dos principais marcos da evolução da contabilidade em Portugal relaciona-se a (OCC, 2017): a) 1759 - Marquês Pombal criou a primeira Aula do Comércio (ensino da contabilidade) e a escola oficial de contabilidade do mundo; b) 1958 - Surge no ordenamento jurídico de Portugal, a profissão de Técnico 
Oficial de Contas, devido à exigência de uma figura consagrada no Código da Contribuição Industrial, em um período de reforma fiscal, que durou de 1958 a 1963. Porém, ainda não haviam normas jurídicas que regulamentassem o exercício da profissão, tampouco a função desses profissionais, limitando-se apenas, à exigir a assinatura deste profissional nas declarações de rendimento e estar inscritos na ex-Direção Geral das Contribuições e Impostos (DGCI); c) 1995 - O Decreto Lei $n^{\circ}$ 265/95 aprova o Estatuto dos Técnicos Oficiais de Contas e a regulamentação da profissão. Com isso, passam a ser exigidas responsabilidades aos profissionais contábeis. Também surge a Associação dos Técnicos Oficiais de Contas (ATOC), onde passa a ser obrigatória a inscrição do profissional para exercer a profissão; e d) 2000 - entra em vigor, o Código Deontológico dos Contabilistas Certificados, com o objetivo de impor regras comportamentais aos profissionais.

\subsection{Evolução da contabilidade no Brasil}

O Brasil está dividido nos seguintes períodos (SILVA; ASSIS, 2015): a) Colônia, de 1500 a 1808: Evolução lenta da contabilidade, pois os controles eram utilizados apenas para verificar o lucro das expedições nas práticas exploratórias dos colonizadores; b) Império de 1808 a 1889: significativo avanço na contabilidade, em função das contribuições do intelectuais franceses no governo de D. Pedro II; e c) República, de 1889 a atuais: houve destaques no avanço da contabilidade influenciadas pelas Escola Europeia e da Escola Americana.

A influência da Escola Europeia pode ser destacada com a aprovação da primeira Lei das Sociedades por Ações, através do Decreto 2.627/40 (LUZ, 2015). Ademais, em 1976, com a aprovação da Lei 6.404 (Lei das Sociedades por Ações), o Brasil define "[...] sua opção pelos critérios de registro e mensuração de eventos e pela estrutura dos relatórios contábeis que eram próprias da contabilidade norte-americana" (LUZ, 2015, p. 49).

Os processos de mudanças na contabilidade podem ser provocados por crises, por exemplo, o escândalo da Enron e World Com, e pela globalização (SAYED; KUSSABA; DUARTE, 2017). Para tanto, a Criação do Comitê de Pronunciamentos Contábeis (CPC), em 2005, a promulgação da Lei $n^{\circ}$ 11.638/07 e a Lei $\mathrm{n}^{\circ}$ 11.941/09 evidenciaram diversos ajustes contábeis, buscando harmonizar as regras brasileiras aos padrões internacionais. Sendo assim, ficou decidido, oficialmente, a convergência da estrutura contábil brasileira às Normas Internacionais de Contabilidade (IFRS), provenientes do órgão europeu de normatização contábil International Accounting Standars Board (IASB) (LUZ, 2015). 


\subsection{Profissão contábil}

A profissão contábil no Brasil é regulamentada pelo Decreto Lei $\mathrm{n}^{\mathrm{o}}$ 9295/46 e alterações posteriores, determinando que o exercício da profissão pode ser exercido após conclusão do curso de Ciências Contábeis reconhecido pelo Ministério da Educação (SANTOS; ESPEJO; OLIVEIRA, 2016). Além disso, também deverá ser aprovado no Exame de Suficiência e no Conselho Regional de Contabilidade (CRC) para estar apto e licenciado a exercer a atividade contábil.

A profissão contábil também é regida pelo Código de Ética Profissional do Contador (CEPC) aprovado pela Resolução CFC 1.307/2010. O CEPC objetiva "[...] fixar a forma pela qual se deve conduzir os Profissionais da Contabilidade, quando no exercício profissional e nos assuntos relacionados à profissão e à classe" (CFC, 2017). Silva (2011) faz ainda um paralelo entre o CEPC e o Exame de Suficiência, onde enfatiza a preocupação do CFC com a valorização da profissão e busca selecionar os profissionais éticos, tecnicamente capacitados e em constante aperfeiçoamento.

$\mathrm{O}$ CFC tem como principal finalidade "[...] orientar, normatizar e fiscalizar o exercício da profissão contábil, por intermédio dos Conselhos Regionais de Contabilidade" (CFC, 2017). O CFC (2017) possuía até abril de 2017, 528.391 profissionais contábeis registrados entre técnicos e contadores. Deste número, 39.781 estavam registrados no Rio Grande do Sul. Neste mesmo período, encontravam-se registradas 59.392 organizações contábeis (entre elas, sociedades, empresários, MEI e EIRELI), sendo que, destas, 3.795 estavam localizadas no Rio Grande do Sul.

Em Portugal, o órgão regulador da profissão é a Ordem dos Contabilistas Certificados (OCC), regido pelo Decreto-Lei n ${ }^{\circ} 139 / 2015$, com um total de 75.000 membros inscritos. A OCC tem como “[...] missão regular e disciplinar o exercício da profissão de contabilista para, além de desenvolver todas as ações conducentes, à uma maior credibilização e dignificação da profissão" (OCC, 2017).

A OCC determina que, para ser Contabilista Certificado, o profissional deve atender os seguintes requisitos: a) Possuir as habilidades acadêmicas necessárias; b) Realização de estágio profissional; e c) Realizar o exame profissional. Os profissionais contábeis de Portugal, devem seguir as normas descritas no Código Deontológico dos Contabilistas Certificados (CDCC), que se aplica a "[...] todos os contabilistas certificados com inscrição em vigor, que exerçam a sua atividade em regime de trabalho dependente ou independente, integrados ou não em sociedades de profissionais, ou em sociedades de contabilidade".

O CDCC é composto por questões relacionados a responsabilidade, competência, princípios contábeis, contrato de trabalho, honorários, entre outros, do profissional contábil (OCC, 2017). Assim como no Brasil, em 
Portugal também é obrigatória a realização de uma proficiência, para obtenção do registro no órgão regulador da profissão contábil. Portanto, para aprovação no Exame de Avaliação Profissional da OCC, o candidato necessita atingir 50\% da nota máxima atribuída à prova (OCC, 2017).

Portanto, para requerer a inscrição como contabilista em Portugal, não é necessária a graduação específica em Ciências Contábeis como no Brasil, mas sim, o "[...] grau acadêmico de licenciado, mestre ou doutor na área de contabilidade, gestão, economia, ciências empresariais ou fiscalidade conferido por uma instituição de ensino superior portuguesa" (OCC, 2017).

\subsection{Resultados de Estudos Precedentes} Brasil.

Os estudos precedentes apresentados no Quadro 1 relacionam-se ao

Quadro 1 - Resultados de estudos anteriores no contexto brasileiro

\begin{tabular}{|c|c|c|}
\hline Autor (es) & Objetivo do estudo & Principais Resultados \\
\hline $\begin{array}{l}\text { Preis et al. } \\
\text { (2013) }\end{array}$ & $\begin{array}{l}\text { Identificar o perfil dos } \\
\text { estudantes de Ciências } \\
\text { Contábeis em relação } \\
\text { à sua percepção do } \\
\text { mercado de trabalho e } \\
\text { do grau de capacitação } \\
\text { em relação ao seu curso } \\
\text { de graduação. }\end{array}$ & $\begin{array}{l}\text { Os autores identificaram que } 36,36 \% \text { almejavam } \\
\text { atuar como servidores públicos e apenas } 6,82 \% \\
\text { acreditavam ser rentável a abertura de um } \\
\text { escritório de contabilidade, figurando essa } \\
\text { opção, como a última colocada na pesquisa. }\end{array}$ \\
\hline Viali (2014) & $\begin{array}{l}\text { Identificar as áreas de } \\
\text { atuação priorizadas } \\
\text { pelos formandos de } \\
\text { ciências contábeis para } \\
\text { o exercício da profissão. }\end{array}$ & $\begin{array}{l}\text { Como resultado, identificou-se que } 44,44 \% \\
\text { dos respondentes, acreditavam que, para } \\
\text { ser um profissional de sucesso e ter uma boa } \\
\text { estabilidade financeira, a melhor área é a } \\
\text { contabilidade pública. }\end{array}$ \\
\hline $\begin{array}{l}\text { Sorgetz et } \\
\text { al. (2014) }\end{array}$ & $\begin{array}{l}\text { Identificar as áreas } \\
\text { da contabilidade } \\
\text { mais desejadas pelos } \\
\text { acadêmicos formandos } \\
\text { do curso de ciências } \\
\text { contábeis. }\end{array}$ & $\begin{array}{l}\text { Observou-se que, cerca de } 43 \% \text { dos } \\
\text { entrevistados, indicavam os cargos públicos } \\
\text { como áreas mais desejadas. Em seguida, } \\
\text { apareceram as áreas tributárias, com um } \\
\text { índice de } 16 \% \text {. Com relação à remuneração, os } \\
\text { formandos acreditavam que a área pública é a } \\
\text { que melhor remunera, representando } 52,27 \% \\
\text { dos entrevistados, seguindo pela área da } \\
\text { auditoria }(29,54 \%) \text {. }\end{array}$ \\
\hline
\end{tabular}




\begin{tabular}{|l|l|l|}
\hline Autor (es) & Objetivo do estudo & Principais Resultados \\
\hline $\begin{array}{l}\text { Ferreira e } \\
\text { Angonese } \\
(2015)\end{array}$ & $\begin{array}{l}\text { Averiguar quais são } \\
\text { as expectativas dos } \\
\text { formandos em ciências } \\
\text { contábeis a realidade } \\
\text { do mercado de trabalho } \\
\text { para os contadores. }\end{array}$ & $\begin{array}{l}\text { Identificou-se que, nas pesquisas das vagas } \\
\text { oferecidas pelo mercado, 43\% eram ofertadas } \\
\text { por escritórios de contabilidade e 25\% dos } \\
\text { candidatos se interessa pela atuação em } \\
\text { escritórios. A abertura de um escritório } \\
\text { de contabilidade representa 21\% dos } \\
\text { entrevistados. }\end{array}$ \\
\hline $\begin{array}{l}\text { Marques, } \\
\text { Dias e Silva } \\
(2017)\end{array}$ & $\begin{array}{l}\text { Analisaras expectativas } \\
\text { profissionais dos } \\
\text { estudantes de ciências } \\
\text { contábeis. }\end{array}$ & $\begin{array}{l}\text { Os resultados indicaram uma pretensão salarial } \\
\text { de 10 a 13 salários mínimos após três anos de } \\
\text { formados. As áreas de interesse compreendem } \\
\text { a Auditoria e Perícia, e de menor interesse, as } \\
\text { áreas de Ensino e Pesquisa e de Mercado de } \\
\text { Capitais. }\end{array}$ \\
\hline
\end{tabular}

Fonte: Elaborado pelo autor.

Estes estudos apontam que a região e a instituição de ensino do acadêmico tem influência significativa sobre suas percepções e respostas. Tal fato demonstra a importância desta análise e confrontação entre os estudos, buscando identificar e solucionar possíveis problemas. Batista (2014) destaca que das atividades econômicas desenvolvidas em Portugal, cerca de $10 \%$ é representado pelo exercício de "Atividades de Consultoria, científicas, técnicas e similares", onde se enquadra a contabilidade, representando assim, menos de 3\% do total de volume de negócios das empresas portuguesas.

Batista (2014) ainda reflete sobre um decréscimo tanto no número de empresas neste ramo (11\%), quanto de pessoal (8\%), tendo os anos 2008 a 2012 em análise. Este fato pode ser explicado em função da crise econômica, instalada em Portugal, principalmente, no período de 2010 para 2011; e pelo aumento das restrições do acesso à profissão e a diminuição da taxa de aprovação do exame da ordem.

\section{PROCEDIMENTOS METODOLÓGICOS}

\subsection{Classificação da pesquisa}

A abordagem, deste pesquisa, é quantitativa, pois sua principal característica é a utilização de instrumentos estatísticos na coleta e no tratamento dos dados (BEUREN, 2009). Para Sampieri, Collado e Lucio (2013) o enfoque quantitativo utiliza a coleta de dados para testar hipóteses, estabelecer padrões e comprovar teorias com base na medição numérica e na análise estatística. Deste modo, caracteriza-se como quantitativa por coletar e analisar os dados objetivos mediante teste Spearman.

O procedimento técnico utilizado é a survey por meio de questionário fechado, pois "[...] caracterizam-se pela interrogação direta das pessoas cujo 
comportamento se deseja conhecer" (GIL, 2002, p. 50). Sendo assim, neste estudo aplica-se um questionário fechado para a coleta dos dados vinculados ao problema de pesquisa. Quanto ao objetivo esta pesquisa é descritiva, pois identificou-se as perspectivas profissionais de determinado grupo de estudantes, suas áreas de maior preferência e o motivo para tal escolha.

\subsection{Unidade de análise e coleta dos dados}

A unidade de análise contou com uma população de 212 estudantes, sendo 127 estudantes do regime diurno e 85 do regime pós-laboral, do curso de contabilidade e finanças do IPL de Leiria, Portugal. A amostra selecionada é não probabilística, ou seja, por acessibilidade, de 72 estudantes, sendo 32 do segundo e 40 do terceiro ano, representando cerca de $34 \%$ do total de estudantes do curso. Diante disto, aproveitando a oportunidade oferecida pela UNIVATES, esta pesquisa foi realizada em Portugal com o intuito de agregar ao intercâmbio realizado no País.

A coleta de dados ocorreu por meio de questionário, contendo 14 questões mistas (ANEXO A), estruturadas de forma em que, inicialmente, seja identificado o perfil do respondente e, em seguida, busque identificar suas perspectivas profissionais quanto às áreas de atuação, interesse, remuneração e inserção no mercado, e por fim, identifique a satisfação do acadêmico em relação à sua preparação para atuar no mercado de trabalho fornecida pelo curso e universidade.

Este questionário foi elaborado, após conversar com dois docentes da IPL para entender a realidade vivida pelos estudantes. Posteriormente, foi realizada a aplicação do pré-teste com três estudantes, onde foi necessário efetuar alguns ajustes para compreensão das questões, devido à diferença de termos específicos da linguagem e gramática portuguesa. Concluído o questionário, o mesmo foi submetido à análise da coordenadora do curso de Contabilidade e Finanças do IPL, Leiria, Portugal, que autorizou sua aplicação com os discentes do curso.

O questionário foi aplicado em maio 2017, de forma impressa, em três salas de aulas e em diferentes horários, sendo, respectivamente, nas disciplinas de Contabilidade Pública, do terceiro ano e regime diurno, Contabilidade de Finanças III também do regime diurno, e Contabilidade de Gestão II, do regime pós-laboral, sendo estas do segundo ano. Da mesma forma, em jun. 2017 foi aplicada aos estudantes da disciplina de Contabilidade Pública, do regime pós-laboral. O tempo médio de preenchimento de cada questionários foi de 15 minutos.

\subsection{Tratamento, análise dos dados e a limitação dos resultados}

Os dados coletados foram tabulados com auxílio do Software Microsoft Office Excel, sendo que as perguntas foram elencadas em colunas, e as respostas 
em linhas, o que possibilitou, através da fórmula "CONT.SE", identificar a quantidade de respostas para cada alternativa. A partir desses dados foi possível realizar a análise de frequência de cada questão.

A análise das correlações ocorreram por meio do teste Spearman, devido às características dos dados serem não paramétricas e nominais (BISQUERRA; SARRIERA; MARTÍNEZ, 2004). A execução da correlação de Spearman foi realizada com auxílio do Software IBM SPSS Statistics 23.

O coeficiente de correlação de Spearman "[...] é uma medida de associação que exige que ambas as variáveis se apresentem em escala de mensuração pelo menos ordinal" (GUIMARÃES, 2017, p. 10). Neste sentido, ela é utilizada para identificar se as variáveis estão associadas e em qual o grau de associação (GUIMARÃES, 2017).

Com relação ao cálculo, Guimarães (2017 p. 10) afirma que "o coeficiente de correlação de Spearman se utiliza da expressão do coeficiente de Pearson, porém calculado com postos". O resultado da correlação de Spearman se centram entre -1 e 1, sendo que, segundo Mitra e Lankford (1999), a intensidade desta correlação avalia-se da seguinte forma: se a correlação estiver entre 0,20 a 0,39 é considerada baixa; entre 0,40 a 0,59 moderada; e acima de 0,59 é considerada forte. Dessa forma, para o cálculo da correlação através do Software IBM SPSS Statistics 23, cada questão foi representada por um algarismo (de 1 a 14) e, da mesma forma, cada alternativa, variando conforme a quantidade de opções.

As principais limitações desta pesquisa relacionam-se a percepção que as pessoas tem de si mesmas, pois este fato pode gerar dados distorcidos, devido à diferença do que as pessoas dizem para o que elas realmente pensam (GIL, 2002). Este também afirma que, os levantamentos tem uma limitada apreensão do processo de mudança, proporcionando apenas uma visão estática do fenômeno em estudo e, assim, alterações no perfil socioeconômico dos estudantes, podem resultar em mudanças nas respostas. Além destas, deve ser destacado que por não ser probabilística, os resultados limitam-se à amostra pesquisada.

\section{RESULTADOS E ANÁLISES}

\subsection{Perfil dos discentes de Contabilidade e Finanças do IPL}

A análise do gênero revela que a maioria (58\%) dos estudantes são femininos (FIGURA 1- QUESTÃO 1). No Brasil, a maioria dos estudantes em contabilidade são do gênero feminino, a saber, Marques, Dias e Silva (2017) em Minas gerais de 74\%, Viali (2014) no Distrito Federal de 59\%, Lubina (2016) em Irati-PR de 51\%. Portanto, conforme pesquisa realizada em IPL e em cidades brasileiras, observa-se que o número de estudantes do gênero feminino é superior ao masculino, alterando assim, um cenário que era ocupado por uma maioria masculina. 
Figura 1 - Perfil dos discentes em Contabilidade e Finanças do IPL - Portugal

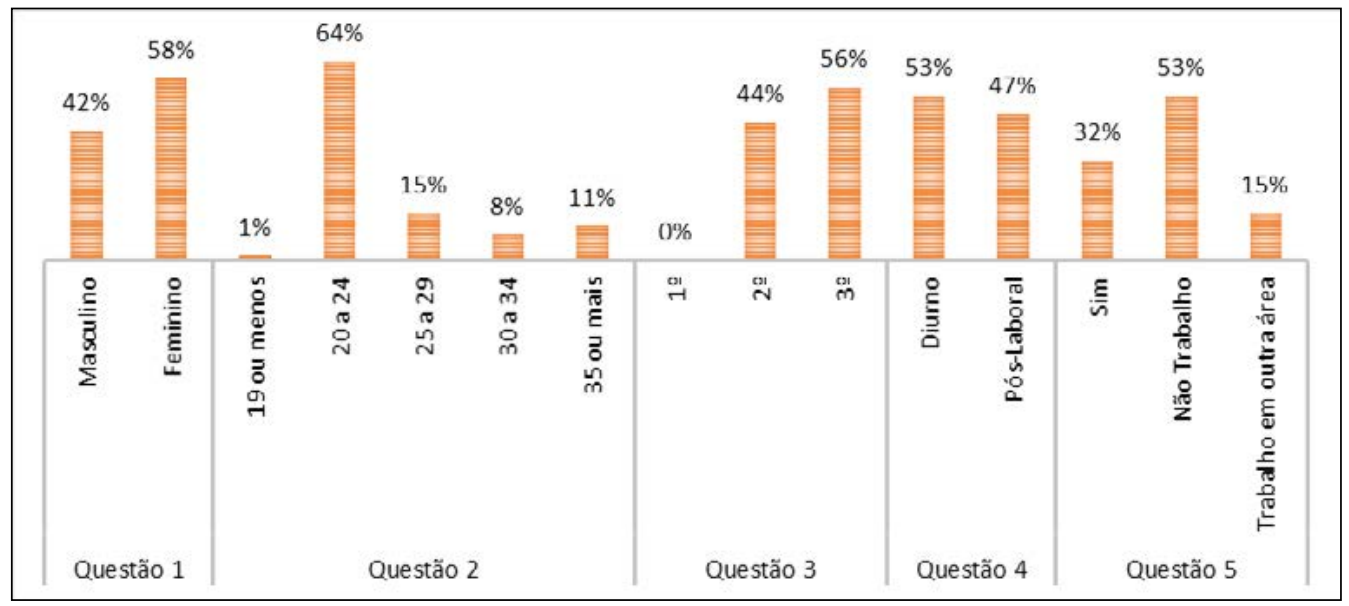

Fonte: Elaborado pelos autores

A faixa etária dos estudantes de Contabilidade e Finanças do IPL (QUESTÃO 2) aponta que 64\% dos entrevistados tem entre 20 e 24 anos. No Brasil, Viali (2014) revela $27 \%$ (20 a 24 anos), $18 \%$ (25 a 29 anos) e $20 \%$ ( $>45$ anos). Martins (2017) em Goiás constatou que 65\% dos concluintes do curso de Ciências Contábeis tinham entre 20 e 24 anos. Souza (2014) na Paraíba revela que entre $55 \%$ a $80 \%$ dos alunos tem entre 20 a 25 anos. Percebe-se que a maioria dos estudantes de contabilidade, tanto no Brasil, como em Portugal, estão na faixa etária de 20 a 25 anos.

Os acadêmicos do IPL de Contabilidade e Finanças são estudantes do $2^{\circ}(44 \%)$ e $3^{\circ}(56 \%)$ anos do curso, ou seja, concluintes (QUESTÃO 3). É importante considerar o ano do curso do estudante, pois suas respostas podem variar à medida em que este tem contato com novas experiências, disciplinas e professores, proporcionados pelas instituições de ensino.

No IPL o curso de Contabilidade e Finanças é oferecido nos turnos diurno (53\%) e pós-laboral (47\%), ver Questão 4. Já na região do Vale do Taquari/RS, existe outra realidade, onde o curso de Ciências Contábeis da Universidade Univates é oferecido apenas no turno pós-laboral, ou seja, noturno. O motivo deste desencontro é demonstrado na Questão 5, na ocupação dos respondentes, pois $53 \%$ dos estudantes portugueses que não trabalham cursam no período diurno, sendo assim, se dedicam em tempo integral aos estudos. Patussi (2015) revela que em Lajeado-RS (Univates) $94 \%$ dos estudantes atuam no mercado de trabalho e $65 \%$ atuam na área contábil; Silva, Santana e Meirelles Junior (2017) constataram que em Volta Redonda $86 \%$ trabalham e destes $67 \%$ na área contábil; Viali (2014) atesta que $91 \%$ trabalham e em torno de $46 \%$ atuando na área; Lubina (2016) identificou que 91,66\% trabalhando enquanto cursam contabilidade. 
Tais pesquisas demonstram a diferença da realidade vivenciada pelos estudantes de contabilidade portugueses com a dos brasileiros. Além da diferença cultural dos dois países, o que também justifica essa discrepância, é a questão financeira. Neste sentido, observou-se que, para parte dos estudantes portugueses (53\%), o custo dos estudos eram quitados pelos pais.

O fato da maioria dos estudantes do IPL não trabalharem, ou trabalharem em áreas adversas à contabilidade, demonstrou a importância desta para o desenvolvimento da aprendizagem do aluno. Ficou evidente que, quando o estudante detém alguma experiência profissional vinculada à contabilidade, isto o possibilita a fazer associações da teoria com a prática, assimilando o conteúdo com elevada facilidade. Sendo assim, os acadêmicos sem essa experiência, podem apresentar dificuldades em assimilar o conteúdo e sua aplicabilidade prática.

\subsection{Percepção dos estudantes quanto ao mercado de trabalho}

A oportunidade de emprego na área, após concluírem o curso de contabilidade e Finanças em IPL, é considerada "boa" em 67\% e como "excelentes" e "razoável" oportunidades em 17\% cada (FIGURA 2 - QUESTÃO 6). Nos estudos de Lubina (2016) foi constatado que 34,7\% consideram "Excelentes" e 34,6\% "boas"; e Neutzling (2014) em Taquara - RS revela que $43 \%$ são "excelentes" e $52 \%$ são "boas".

Figura 2 - Percepção dos discentes em relação ao mercado de trabalho.

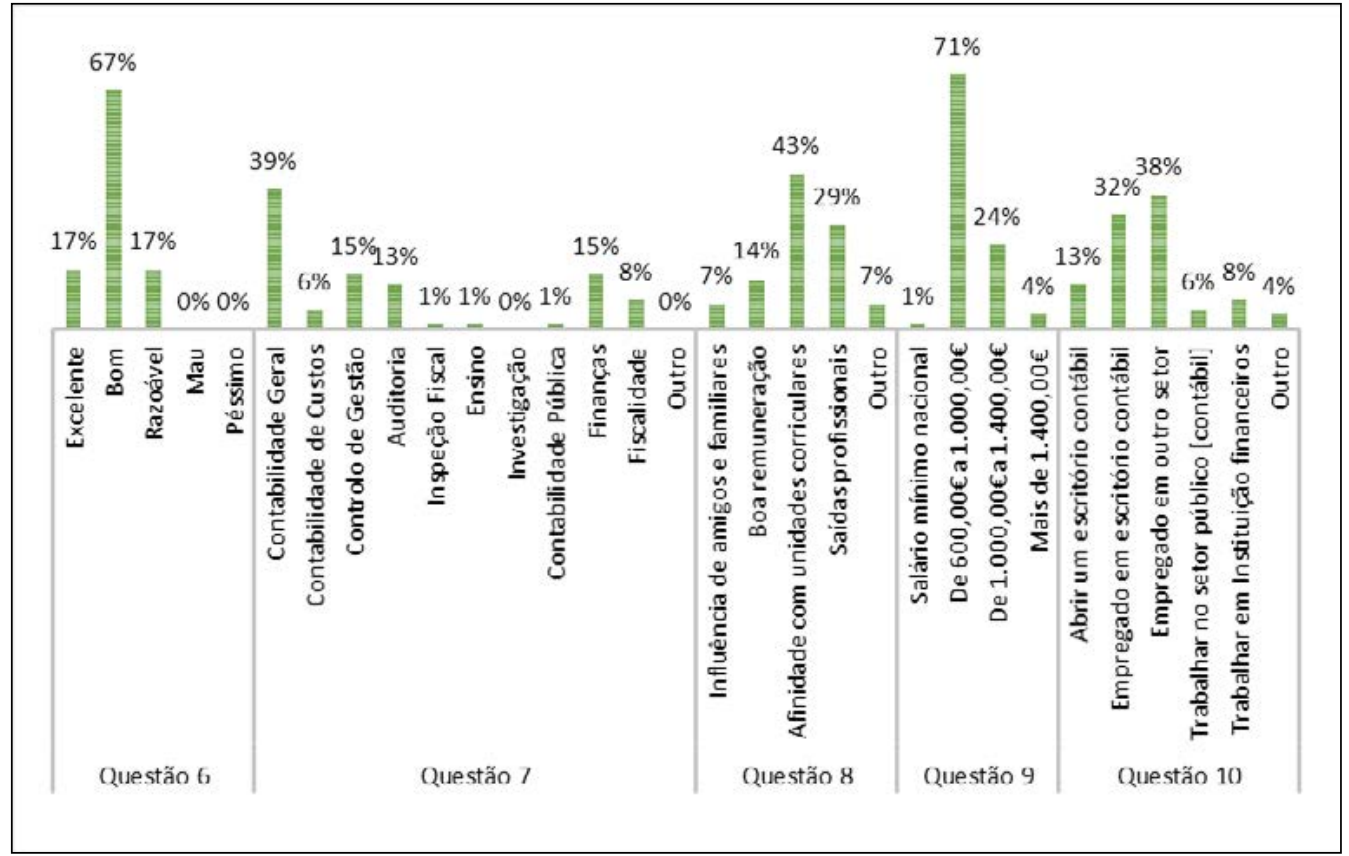

Fonte: Elaborado pelos autores. 
A área de interesse dos discentes revela uma inclinação à contabilidade geral (39\%), contabilidade de custos e finanças com $15 \%$ cada (QUESTÃO 7). Estudo precedente de Martins (2017) aponta a área contábil e contabilidade pública com 21,7\% cada; Marques, Dias e Silva (2017) revelam as áreas de Auditoria e Perícia com 59\% das preferências. Neste caso, os estudos não apresentam afinidade quanto aos resultados.

$\mathrm{O}$ interesse em determinada área da contabilidade tem aderência a afinidade com as disciplinas relacionadas com 43\% (QUESTÃO 8), onde o docente pode contribuir por meio da forma como leciona a disciplina, também apontado por Maudline, Crain e Mounce (2000). Além disso, relacionam o interesse com a área de maior possibilidade de vagas de empregos (29\%). E, por fim, o interesse frente a área relaciona-se a influência da remuneração (14\%).

A expectativa de remuneração após conclusão do curso pelos discentes é de 600,00 a 1.000,00 Euros com 71\% (QUESTÃO 9) e 24\% dos discente almeja uma remuneração de 1.000,00 a 1.400,00 Euros. No Brasil, Lubina (2013) identificou que em torno de 70\% dos estudantes almeja acima de 3.390,00 Reais; Neutzling (2014) identificou que 50\% dos acadêmicos almeja 4.344,00 a 7.240,00 Reais. Nota-se que os acadêmicos possuem expectativas de remuneração nestes estudos, porém Malgwi, Howe e Burnaby (2005) e Umar (2015) enfatizam que o incentivo financeiro não pode ser considerado o único fator que influencia na escolha da profissão contábil.

A análise do objetivo profissional dos acadêmicos do IPL do curso de contabilidade aponta a atuação em empresa privada (38\%) e em escritório de contabilidade (32\%) (QUESTÃO 10). Em estudos anteriores, por exemplo, Ferreira e Angonese (2015) em Porto Alegre - RS apontam que 25\% dos estudantes objetivam atuar em escritório de contabilidade, $21 \%$ abertura de escritório contábil e $21 \%$ no setor público; Rodrigues (2014) em Cacoal Rondônia aponta que a preferência é a gestão pública (20,5\%); e Martins (2017) identificou que $24 \%$, pretendem atuar na esfera pública. Dessa forma, observase uma diferença dos objetivos profissionais dos acadêmicos, sendo que a perspectiva é distinta dependendo da região.

\subsection{Percepção dos estudantes quanto à formação}

O fato complicador da inserção no mercado de trabalho, na visão dos acadêmicos, é a falta de experiência e a falta de oportunidade (FIGURA 3 QUESTÃO 11). A pesquisa de Ferreira e Angonese (2015) aponta que 9\% das vagas na área da contabilidade não exigem experiência precedente, enquanto $43 \%$ das vagas exigem um ano de experiência. Apesar desta pesquisa ter sido realizada no Brasil, de certa forma justifica a preocupação dos alunos portugueses, pois $53 \%$ dos discentes não trabalham no curso de contabilidade e finanças da IPL. Rodrigues (2014) aponta que 68\% dos acadêmicos entendem que há influencia entre a inserção no mercado de trabalho e a formação recebida pela IES, pois carecem de aulas práticas, estágios, experiência profissional, entre 
outros. Neste sentido, Neutzling (2014) identificou que, 62\% dos respondentes, acreditam que a dificuldade centra-se na falta de experiência.

Figura 3 - Percepção dos discentes diante da formação

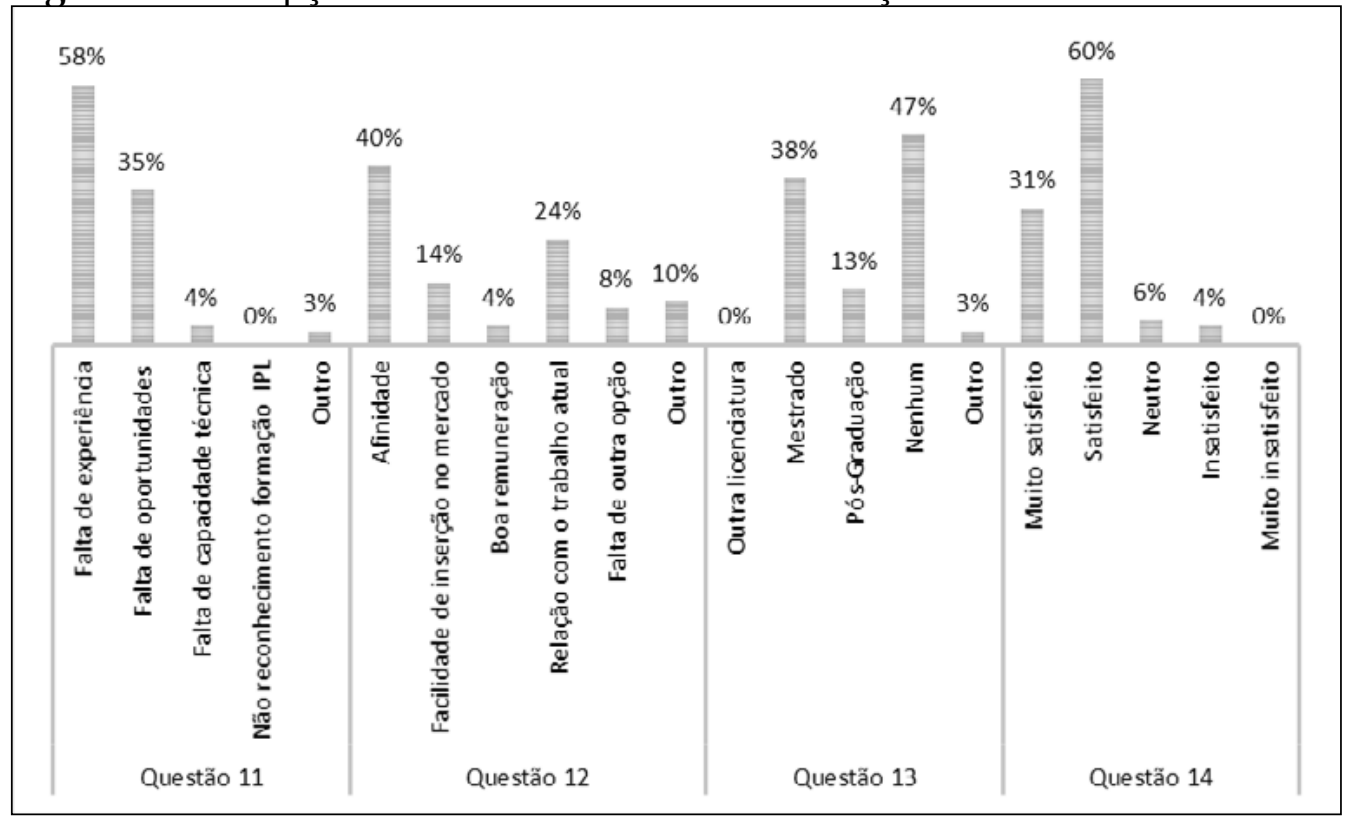

Fonte: Elaborado pelos autores

A motivação do acadêmico na escolha do curso está relacionada pela sua afinidade $(40 \%)$, pela relação com o atual emprego (24\%) e apenas $4 \%$ em função da remuneração (QUESTÃO 12). Nos estudos de Rodrigues (2014) foi identificado que $43 \%$ dos respondentes optou pelo curso de Ciências Contábeis devido à oportunidade de mercado, e em relação com o trabalho atual $(15 \%)$; Viali (2014) apontou que 52\% ocorreu em função das oportunidades do mercado de trabalho; Neutzling (2014) identificou o mercado de trabalho (53\%) e a satisfação pessoal (30\%); e Pattussi (2015) apontou o gosto e a identificação pela área (44\%) e a oferta de emprego na área (33\%). Estes dados reforçam que a motivação é influenciada por variáveis distintas, conforme Rababah (2016).

Os acadêmicos tem interesse, após conclusão da graduação, de não continuar estudando (47\%), cursar mestrado (38\%) e especialização $(13 \%)$ (QUESTÃO 13). Patussi (2015) aponta a não continuação dos estudos (11\%), especialização $(56 \%)$ e mestrado $(28 \%)$; Viali (2014) revela a prestação de concurso $(40 \%)$, especialização (32,5\%), mestrado (10\%); Ribeiro, Oliveira e Arenas (2016), em Rondônia, aponta a especialização (38\%), mestrado (21\%) e nenhuma (17\%). Nota-se que os estudantes Portugueses distinguem-se dos Brasileiros, pois estes últimos sugerem ser favoráveis em continuar estudando. 
O nível de satisfação do acadêmico frente ao curso é de "satisfeito" e "muito satisfeito" de $60 \%$ e $31 \%$, respectivamente. Em estudo precedentes Ribeiro, Oliveira e Arenas (2016) apontam que o conhecimento adquirido não foi suficiente para encarar o mercado (53\%) e apenas $15 \%$ dos respondentes acreditavam ter adquirido conhecimento suficiente. Viali (2014) revelou que $70 \%$ dos respondentes estão "satisfeitos" com o curso e 15\% "muito satisfeitos" e Neutzling (2014) identificou que, 80\% dos respondentes, se consideravam "satisfeitos" e 13\% "plenamente satisfeitos".

\subsection{Teste de Spearman}

Nesta subseção analisa-se as variáveis independentes que afetam significativamente o comportamento do acadêmico do curso de contabilidade e Finanças da IPL (TABELA 1). Os resultados da correlação de Spearman não apontam significâncias com alta intensidade, conforme classificação de Mitra e Lankford (1999).

Tabela 2 - Correlação de Spearman

\begin{tabular}{|c|c|c|c|c|c|c|c|c|c|c|c|c|c|c|}
\hline & Q1 & $\mathrm{Q} 2$ & Q3 & $\mathrm{Q} 4$ & Q5 & Q6 & Q7 & Q8 & Q9 & Q10 & Q11 & Q12 & Q13 Q1 & \\
\hline Q1 & 1 & & & & & & & & & & & & & \\
\hline Q2 & 0,18 & 1 & & & & & & & & & & & & \\
\hline Q3 - & $-0,019$ & 0,171 & 1 & & & & & & & & & & & \\
\hline $\mathrm{Q} 4$ & 0,179 &, $660^{* *}$ & * $286^{*}$ & 1 & & & & & & & & & & \\
\hline Q5 - & $-0,179$ & $-0,18$ &,$- 241^{*}$ &,$- 311^{* *}$ & 1 & & & & & & & & & \\
\hline Q6 & 0,098 & $-0,039$ & $-242^{*}$ & $-0,193$ & 0,149 & 1 & & & & & & & & \\
\hline Q7 & $-0,084$ & $-0,131$ & 0,037 & $-0,116$ & ,278* & 0,03 & 1 & 1 & & & & & & \\
\hline Q8 & $296^{*}$ & 0,152 & $-0,167$ & 0,04 & $-0,069$ & 0,124 & $-0,219$ & 1 & & & & & & \\
\hline Q9 & $-0,159$ & $439^{* * *}$ & 0,081 &, $349^{* *}$ & $-0,147$ & $-0,087$ & $-0,015$ & $5-0,115$ & 1 & & & & & \\
\hline Q10 & 0,021 & 0,031 & 0,217 & 0,101 & 0,111 & 0,101 & $402^{* *}$ & *,$- 296^{*}$ & * $-0,019$ & 1 & & & & \\
\hline Q11 & 0,083 &, $356^{* *}$ & $-0,026$ & 0,112 &,$- 311^{* *}$ & $-0,066$ & 0,061 & 10,046 & $5,312^{* *}$ & * $241^{*}$ & 1 & & & \\
\hline Q12 & 0,009 & 0,158 & $-0,004$ & 0,067 & $-0,087$ & $-0,089$ & $-0,05$ & $5,234^{*}$ & 0,2 & $2-0,229$ & 0,121 & 1 & & \\
\hline Q13 & $-0,17$ & $-277^{*}$ & * 0,083 & $-0,107$ & $-0,034$ &,$- 291^{*}$ & 0,16 & $6-0,112$ & $-0,125$ & 0,011 & $-0,058$ & $-0,019$ & 1 & \\
\hline Q14 & $234^{*}$ & $-0,012$ &,$- 307^{* *}$ & $-0,18$ & 0,091 &, $381^{* *}$ & $-0,074$ & $4,258^{*}$ & $-0,165$ & $5-0,191$ & $-0,191$ & 0,009 & $-0,196$ & 1 \\
\hline
\end{tabular}

Fonte: Elaborado pelo autor. Legenda: * A correlação é significativa no nível 0,05 (bilateral). ${ }^{* *} \mathrm{~A}$ correlação é significativa no nível 0,01 (bilateral).

As correlações analisadas centram-se com significância no nível 0,01 e com intensidade igual ou superior a 0,35, considerando a classificação de Mitra e Lankford (1999). Sendo assim, a expectativa de remuneração após a conclusão do curso (QUESTÃO 9), onde $p=0,439$ e o fator que dificulta a inserção no mercado de trabalho (QUESTÃO 11), onde $p=0,356$ são influenciadas pela variável faixa etária (QUESTÃO 2). Sendo assim, quanto maior a faixa etária do 
estudante, maior é a expectativa de remuneração e a dificuldade de inserção no mercado.

Em vista disto, Bandeira (2014), sugere que os acadêmicos estão cientes que sua idade é fator determinante para sua remuneração, mas não somente por isto, mas pelo conhecimento e experiência que estão atrelados. Silva e Kassouf (2002) destacam que é natural que os jovens possuam experiência profissional e, sendo assim, quem o tiver, terá vantagem em relação aos demais. Neves, Gonçalves e Lima (2015), salientam que a experiência é uma importante variável e determinante para a participação no mercado de trabalho.

\section{CONCLUSÃO}

O entendimento das expectativas futuras dos acadêmicos em contabilidade torna-se importante na medida que pode-se acompanhar as áreas com maior afinidade e as necessitadas, pois a área contábil é dinâmica. Sendo assim, este estudo analisou as perspectivas dos estudantes de Contabilidade e Finanças do IPL de Leiria, Portugal, quanto à profissão contábil e sua comparação com o Brasil.

O perfil dos acadêmicos de contabilidade e finanças do IPL, Leiria, Portugal, são em sua maioria do gênero feminino, entre 20 e 24, estudam no diurno e pós-laboral, não trabalham e aqueles que trabalham não atuam na área da contabilidade. A perspectiva futura da área na qual querem atuar relacionase a contabilidade geral e não preferem na área da fiscalidade e pública. A maioria tem a perspectiva de ganhar em termos de remuneração até 1.000,00 Euros.

A perspectiva dos acadêmicos em relação a profissão centra-se em atuar em empresa privada e escritório de contabilidade, a menor perspectiva relaciona-se na atuação em instituição financeira e no setor público. As variáveis que influenciam nas expectativas futuras dos acadêmicos relaciona-se a faixa etária, ou seja, quanto maior a faixa etária do estudante, maior é a expectativa de remuneração e a dificuldade de inserção no mercado.

Apesar de haver semelhanças entre a estrutura normativa e de processos da profissão contábil de Portugal e do Brasil, as características relacionadas ao perfil e as perspectivas futuras dos acadêmicos diferem. Neste sentido, o que pode influenciar é a cultura regional, as demandas de mercado, entre outros, que tornam as expectativas distintas e que fogem do escopo deste estudo. Como sugestão para futuros estudos, recomenda-se analisar a perspectiva que o mercado de trabalho tem dos jovens profissionais que estão iniciando sua vida profissional na área da contabilidade, quanto à sua preparação e capacitação técnica para suprir as exigências do mercado. 


\section{REFERÊNCIAS}

BANDEIRA, Rafael Lima. A relação entre remuneração e educação formal na cidade de Lajeado-RS. 75f. 2014. Graduação em administração. Trabalho de Conclusão de Curso. Univates. 2014.

BATISTA, Catarina Isabel da Costa. A evolução da contabilidade e o quotidiano num gabinete de contabilidade. 2014. (Mestrado em Auditoria e Análise Financeira) Instituto Politécnico de Tomar. Escola Superior de Gestão de Tomar.

BISQUERRA, R.; SARRIERA, J. C.; MARTÍNEZ, F. Introdução à estatística: enfoque informático com o pacote estatístico SPSS. Porto Alegre: Bookman, 2007.

BEUREN, Ilse Maria. Como elaborar trabalhos monográficos em contabilidade: teoria e prática. 3. ed. São Paulo: Atlas, 2009.

BUGARIM, Maria Clara Cavalcante et al. Ações do Conselho Federal de Contabilidade no Desenvolvimento da Contabilidade Brasileira. Revista Contabilidade e Controladoria, v. 5, n. 2, 2013.

CFC - CONSELHO FEDERAL DE CONTABILIDADE. Resolução n. 560 de 28 de dezembro de 1983. Prerrogativas Profissionais. Conselho Federal de Contabilidade. Disponível em: <http:/ / www1.cfc.org.br/sisweb/sre/detalhes_sre. aspx?codigo=2000/000898 > . Acesso em: 01 mai. 2017.

CFC - CONSELHO FEDERAL DE CONTABILIDADE. RESOLUÇÃO CFC n. 1.307 de 20 de novembro de 1996. Disponível em: <http: / / www2.cfc.org.br/sisweb/sre/detalhes_ sre.aspx?Codigo=2010/001307\&arquivo=Res_1307.doc $>$. Acesso em: 03 mai. 2017.

CORKERN, Sheree M.; PARKS, Sandra B.; MORGAN, Mark I. Embracing The Future: What Can Accounting Graduates Expect?. American Journal of Business Education (Online), v. 6, n. 5, p. 531, 2013.

DEGENHART, Larissa; TURRA, Salete; BIAVATTI, Vania Tanira. Mercado de trabalho na percepção dos acadêmicos concluintes do curso de Ciências Contábeis do estado de Santa Catarina. ConTexto, v. 16, n. 32, p. 77-93, 2016.

EPOCA.GLOBO. As profissões condenadas a desaparecer - e as que resistirão às novas tecnologias. 2017. Acesso: <http:/ / epoca.globo.com/vida/vida-util/carreira/ noticia/2014/03/bprofissoesb-condenadas-desaparecer-e-que-resistirao-novastecnologias.html>. Acesso: 16/10/2017

FERREIRA, Vagner Paz; ANGONESE, Rodrigo. 2015. O mercado de trabalho para contadores: expectativas e realidades. Disponível em: <http:/ / www.crcrs. org.br/convencao/arquivos/trabalhos/cientificos/mercado_de_trabalho_para_ contadores_804.pdf>. Acesso em: 26 abr. 2017.

GIL, Antonio Carlos. Como Elaborar Projetos de Pesquisa. 4. ed. São Paulo: Atlas S.A., 2002. 
IUDÍCIBUS, Sérgio de, MARION, José Carlos, FARIA, Ana de. Introdução à teoria da contabilidade para o nível de graduação. 5. ed. São Paulo: Atlas, 2012.

LIRA, Miguel Carvalho. Caracterização da Evolução da Contabilidade em Portugal: do século XII a meados do século XVIII. Sociedade, contabilidade e gestão, v. 5, n. 2, 2011.

LUZ, Érico Eleutério da. Teoria da contabilidade. São Paulo: Intersaberes, 2015.

LUBINA, Aline. Perspectivas e do mercado de trabalho dos acadêmicos do curso de ciências contábeis da universidade estadual do centro-oeste de Irati-PR Unicentro. Diálogos Multidisciplinares, v. 1, n. 3, 2016.

MARQUES, Vagner Antônio; DIAS, Keli Cristina Meireles; DA SILVA, Lilian Karolina Correia. Expectativas profissionais dos estudantes de Ciências Contábeis: uma análise em uma instituição de ensino de Minas Gerais. Percurso Acadêmico, v. 6, n. 11, 2017.

MARIN, Tany Ingrid Sagredo; LIMA, Silene Jucelino; NOVA, Silvia Pereira de Castro Casa. Formação do Contador-o que o Mercado quer, é o que ele tem? Um Estudo sobre o Perfil Profissional dos Alunos de Ciências Contábeis da FEA-USP. Contabilidade Vista \& Revista, v. 25, n. 2, p. 59-83, 2015.

MALGWI, C. A.; HOWE, M. A.; BURNABY, P. A. Influences on Students Choice of College Major. Journal of Education for Business, v. 80, n. 5, p. 275-285, 2005.

MAUDLIN, S.; CRAIN, J. L.; MOUNCE, P. H. The Accounting Principles Instructor's influence on Students Desicion to Major in Accounting. Journal of Education for Business, v. 75, n. 2, p. 142-148, 2000.

MEC. Ministério da Educação. Censo da Educação Superior. 2016. Disponível em: <http:/ / portal.mec.gov.br/component/tags/tag/32044-censo-da-educacaosuperior $>$. Acesso em 12/10/2017.

MITRA, A.; LANKFORD, S. Research methods in park, recreation and leisure services. Champaign, ILL: Sagamore; 1999.

NEUTZLING, Marcel; VIER, Ailson José. Perspectivas de futuro mercado pelos acadêmicos de Ciências Contábeis da Faccat. Revista Eletrônica do Curso de Ciências Contábeis, v. 3, n. 4, p. 94-115, 2014.

NEVES, Mateus de Carvalho Reis; GONÇALVES, Marcos Falcão; LIMA, João Eustáquio de. Mundos distintos e realidades semelhantes: empregabilidade dos jovens no Nordeste e Sudeste brasileiros. Revista Brasileira de Estudos de População, v. 32, n. 2, p. 335-356, 2015.

OCC. Ordem dos contabilistas certificados. 2017. Disponível em: < https:/ / www.occ. $\mathrm{pt} / \mathrm{pt} />$. Acesso em 15/10/2017. 
PEREIRA, Lívia; FERREIRA, Marcio Violante. Sequência de Fibonacci: história, propriedades e relações com a razão áurea. Disciplinarum Scientia I Naturais e Tecnológicas, v. 9, n. 1, p. 67-81, 2016.

PEREIRA, B. C. S.; GIL, C. Avaliando a satisfação de alunos de escolas de administração: uma nova perspectiva de gestão. Revista de Administração da UNIMEP, v. 5, n. 1, 2007.

PREIS B. R. S.; CARMO; C. R. S.; CUNHA; F. S.; LIMA; I. G.; OLIVEIRA; M. G.; RIBEIRO; R. G. C. Ensino em contabilidade: uma análise do perfil dos estudantes do curso de ciências contábeis quanto à sua percepção do mercado de trabalho e o seu grau de capacitação. Cadernos da FUCAMP, v. 12, n. 16, p. 60-78, 2013.

RABABAH, Abedalqader. Factors Influencing the Students' Choice of Accounting as a Major: The Case of X University in United Arab Emirates. International Business Research, v. 9, n. 10, p. 25, 2016.

REIS, Anderson de Oliveira et al. Perfil do profissional contábil: Habilidades, competências e imagem simbólica. Congresso Controladoria e Contabilidade USP, v. 55, n. 31, p. 95-116, 2015.

RIBEIRO, Regiane Kelly Minosso; OLIVEIRA, Vanessa Almeida De Marlene; ARENAS, Valerio Dos Santos. As expectativas dos acadêmicos do curso de ciências contábeis da universidade federal de Rondônia em relação ao mercado de trabalho. In: XVI Colóquio Internacional de Gestão Universitária - CIGU, Universidade Federal de Santa Catarina (UFSC), 2016. Anais... Universidade Federal de Santa Catarina (UFSC), 2016.

RODRIGUEZ, Alexandre. Fatores de permanência e evasão de estudantes do ensino superior brasileiro-um estudo de caso. Caderno de Administração. Revista da Faculdade de Administração da FEA. ISSN 1414-7394, v. 5, n. 1, 2012.

RODRIGUES, Diniqueli Nascimento. Mercado de trabalho para o graduado em Ciências Contábeis. 28f. 2014. Fundação Universidade Federal De Rondônia - UNIR. Acadêmico de Ciências Contábeis, 2014.

SAMPIERI, Roberto Hernández; COLLADO, Carlos Fernández; LUCIO, Maria del Pilar Baptista. Métodos de Pesquisa. 5. ed. Porto Alegre: Penso, 2013.

SANTOS, Edicreia Andrade dos; ESPEJO, Marcia Maria dos Santos Bortolocci; OLIVEIRA, Renata Mendes de. Profissão Contábil e o seu Mercado de Trabalho no Âmbito Brasileiro: Uma Análise da Literatura. In: VII Congresso Nacional de Administração e Contabilidade-AdCont 2016. Anais... 2016.

SANTOS, Marcos Aurélio Corrêa; ROMEIRO, Vladimir. A satisfação com a experiência acadêmica influencia a relação de confiança comportamental com a instituição?. Revista Brasileira de Ensino Superior, v. 3, n. 1, p. 78-97, 2017. 
SAYED, Samir; KUSSABA, Cristiane; DUARTE, Sergio Lemos. A Lei das Sociedades Anônimas e o Processo de Convergência para os Padrões Internacionais Contados pela História Oral e de Vida. Revista de Gestão, Finanças e Contabilidade, v. 7, n. 1, p. 252, 2017.

SILVA, Bruna Novais; SANTANA, Cintia Lopes; MEIRELLES JUNIOR, Júlio Candido. Formação acadêmica em Ciências Contábeis e sua relação com o mercado de trabalho: a percepção de formandos de Ciências Contábeis de uma Instituição de Ensino Superior. Revista Brasileira de Contabilidade, n. 225, p. 66-77, 2017.

SILVA, Amanda Samylli et al. A percepção dos concluintes do curso de ciências contábeis acerca das perspectivas mercadológicas: uma analogia entre os alunos das instituições pública e privada do município de Caicó/RN. In: II Congresso UFERSA de Contabilidade 2015. Anais... UFERSA de Contabilidade 2015.

SILVA, Caroline Sanders da. Ética na profissão contábil. 2011.

SILVA, Maurício Souza; DE ASSIS, Francisco Avelino. A história da Contabilidade no Brasil. Negócios em Projeção, v. 6, n. 2, p. 35-44, 2015.

SILVA, Amanda Samylli da et al. 2015. A percepção dos concluintes do curso de ciências contábeis acerca das perspectivas mercadológicas: uma analogia entre os alunos das instituições pública e privada do município de Caicó/RN. Disponível em: <http:/ / fcst.edu.br/site/wp-content/uploads/2016/03/anais-mossoro-2015.pdf>. Acesso em: 26 abr. 2017.

SILVA, N. D. V.; KASSOUF, A. L. A exclusão social dos jovens no mercado de trabalho brasileiro. Revista Brasileira de Estudos de População, v. 19, n. 2, p. 99-115, 2002.

SORGETZ, Eronita Terezinha Segalla et al. Áreas da contabilidade mais desejadas: estudo de caso dos acadêmicos de Ciências Contábeis formandos 2014 da FSG.

Revista de Contabilidade, Ciência da Gestão e Finanças, v. 2, n. 1, p. 4-25, 2014.

SOUZA, Jane Fonda Domingos de. Perfil e perspectivas da profissão contábil para os formandos em Ciências Contábeis das universidades públicas do estado da Paraíba. 2014. 23 f. Monografia (Graduação) - Curso de Ciências Contábeis, Universidade Estadual da Paraíba, Campina Grande, 12 mai. 2014.

SOUZA, Deyze Moreira de; TAVARES, Juliane Mari Pires. Perspectivas profissionais dos acadêmicos do curso de Ciências Contábeis e as expectativas de demanda do mercado. 2013. 66 f. Monografia (Graduação) - Curso de Ciências Contábeis, Universidade Tecnológica Federal do Paraná, Pato Branco, 29 jan. 2013.

SOUZA, Saulo Aparecido; REINERT, José Nilson. Avaliação de um curso de ensino superior através da satisfação/insatisfação discente. Avaliação: Revista da Avaliação da Educação Superior, v. 15, n. 1, 2010. 
UMAR, Ibrahim. Factors influencing students' career choice in accounting: The case of Yobe State University. Research Journal of Finance and Accounting, v. 5, n. 17, p. 59-62, 2014.

VIALI, Adriano Souza. Análise das intenções dos formandos no curso de ciências contábeis na escolha da área de atuação no mercado de trabalho. 2014. $31 \mathrm{f}$. Monografia (Graduação) - Curso de Ciências Contábeis, Centro Universitário de Brasília, Brasília, 05 set. 2014.

Anexo A - Questionário para Trabalho de Conclusão de Curso

Este questionário é parte integrante de uma pesquisa cientifica, e tem como objetivo identificar as perspectivas dos estudantes de Contabilidade e Finanças do IPL, quanto a profissão contábil.

1. Qual é o seu gênero?

O Masculino

O Feminino

2. Qual é a sua faixa etária?

O 19 ou menos

O 20 a 24

O 25 a 29

O 30 a 34

O 35 ou mais

3. Em qual ano está matriculado?

$\mathrm{O} 1^{\mathrm{o}}$

$\mathrm{O} 2^{\circ}$

$\mathrm{O} 3^{\circ}$

4. Qual o regime?

O Diurno

O Pós-Laboral

5. Sua atuação profissional vincula-se a área da contabilidade?

O Sim

O Não trabalho 
O Trabalho em outra área

- Qual?

6. Qual é a importância do curso de Contabilidade e Finanças quanto a geração de oportunidades de trabalho?

O Excelente

O Boa

O Razoável

O Péssima

7. Qual é a área de atuação que tens interesse em seguir na sua vida profissional?

O Contabilidade Geral

O Contabilidade de Custos

O Controlo de Gestão

O Auditoria

O Peritos Fiscais

O Ensino

O Investigação

O Contabilidade Pública

O Finanças

O Fiscalidade

O Outro

- Qual?

8. Quais são os fatores que te motivaram na preferência da questão anterior?

O Influência de amigos e familiares

O Boa remuneração

O Afinidade

O Disciplina do curso

O Saídas profissionais

O Outro

- Qual? 

curso?

9. Qual é sua expectativa de remuneração mensal, após a conclusão do
O Salário mínimo nacional
O De $600,00 €$ a $1.000,00 €$
O De $1.000,00 €$ a $1.400,00 €$
O Mais de $1.400,00 €$ contabilidade?

10. Qual é seu objetivo profissional após a conclusão do curso de

O Constituir um escritório de contabilidade

O Trabalhar como colaborador em um escritório de contabilidade

O Trabalhar em empresa privada

O Trabalhar no setor público

O Trabalhar em instituição financeira

O Outro

- Qual

11. Quais os fatores intervenientes que podem dificultar a sua inserção no mercado de trabalho?

O Falta de experiência

O Falta de oportunidades do mercado de trabalho

O Falta de capacidade técnica

O Outro

- Qual?

12. Qual é o motivo da escolha do curso de Contabilidade e Finanças?

O Afinidade

O Facilidade de inserção no mercado de trabalho

O Boa remuneração

O Relação com o trabalho atual

O Falta de opção

O Outro

- Qual?

13. Qual é seu objetivo acadêmico após a conclusão do curso? 
O Outra Licenciatura

O Mestrado

O Especialização

O Nenhum

O Outro

- Qual?

14. Qual o seu nível se satisfação quanto ao desenvolvimento das habilidades e competências necessárias para o exercício da profissão de contabilista, fornecido pelo curso de Contabilidade e Finanças da IPL?

O Muito satisfeito

O Satisfeito

O Neutro

O Insatisfeito

O Muito Insatisfeito 